Saint Louis University School of Law

Scholarship Commons

All Faculty Scholarship

2017

\title{
A Comparison of Defendants with Mental Illness Represented by Public Defenders and Private Attorneys: an Analysis of Court-Ordered Pretrial Psychiatric Evaluations
}

Donald M. Linhorst

Saint Louis University School of Social Work

P. Ann Dirks-Lindhorst

Southern Illinois University Edwardsville

Susan McGraugh

Saint Louis University School of Law

Lauren Choate

Saint Louis University School of Law

Sarah Riley

Saint Louis University School of Social Work

Follow this and additional works at: https://scholarship.law.slu.edu/faculty

Part of the Criminal Law Commons, $\underline{\text { Criminal Procedure Commons, and the Criminology and }}$ Criminal Justice Commons

\section{Recommended Citation}

Linhorst, D.M., Dirks-Linhorst, P.A., McGraugh, S., Choate, L. \& Riley, S. (2017). A Comparison of Defendants with Mental Illness Represented by Public Defenders and Private Attorneys: an Analysis of Court-Ordered Pretrial Psychiatric Evaluations. Am J Crim Just, 43:810-830.

This Article is brought to you for free and open access by Scholarship Commons. It has been accepted for inclusion in All Faculty Scholarship by an authorized administrator of Scholarship Commons. For more information, please contact erika.cohn@slu.edu, ingah.daviscrawford@slu.edu. 


\title{
A Comparison of Defendants with Mental Illness Represented by Public Defenders and Private Attorneys: an Analysis of Court-Ordered Pretrial Psychiatric Evaluations
}

\author{
Donald M. Linhorst ${ }^{1}$ • P. Ann Dirks-Linhorst ${ }^{2}$ • \\ Susan McGraugh ${ }^{3} \cdot$ Lauren Choate $^{3} \cdot$ Sarah Riley $^{1}$
}

Received: 26 August 2017 / Accepted: 11 December 2017 /

Published online: 18 December 2017

(C) Southern Criminal Justice Association 2017

\begin{abstract}
This study compared the characteristics and court-ordered evaluation questions and responses among 4,430 defendants to determine if differences existed between those represented by public defenders and private attorneys when receiving trial competency or responsibility psychiatric evaluations from a state department of mental health. Defendants represented by public defenders were more likely to be younger, to have less education, to have psychotic disorders, to have a history of inpatient psychiatric treatment, to live in urban or rural counties, and to be jailed at the time of the evaluation. In addition, defendants represented by public defenders were less likely to have a request for a criminal responsibility evaluation and more likely to be evaluated as having a mental illness, to be incompetent to stand trial, and to need hospitalization pending trial. Consideration of whether defendants with public defenders receiving less requests for responsibility evaluations was indicative of a therapeutic jurisprudence approach is discussed. Implications for research on types of legal representation of defendants with mental illness are discussed.
\end{abstract}

Keywords Mental illness $\cdot$ Private attorneys $\cdot$ Public defenders $\cdot$ Pretrial psychiatric evaluations $\cdot$ Competency to stand trial $\cdot$ Criminal responsibility

P. Ann Dirks-Linhorst

pdirks1@siue.edu

1 School of Social Work, Saint Louis University, 3550 Lindell Blvd, St. Louis, MO 63103, USA

2 Department of Criminal Justice Studies, Southern Illinois University Edwardsville, P.O. Box 1455, Edwardsville, IL 62026, USA

3 Criminal Defense Clinic, School of Law, Saint Louis University, 100 N Tucker Blvd, St. Louis, MO 63101, USA 


\section{Introduction}

Representation by an attorney in criminal cases is one of the basic rights of the United States (U.S.) legal system and is protected by the Sixth Amendment to the U.S. Constitution. For those who cannot afford an attorney, the U.S. Supreme Court ruled in Gideon v. Wainwright (1963) that states, in addition to the federal government, must provide an attorney in criminal cases. Since that ruling, all states provide publicly financed legal representation in criminal cases for those who cannot afford an attorney, although states set their own eligibility criteria (Langton \& Farole Jr., 2009). States provide indigent defendants with free legal representation through one or more of three ways: public defenders, assigned attorneys, and contract attorneys (Owens, Accetta, Charles, \& Shoemaker, 2014). In the U.S., public defenders are employees of a governmental agency whose primary function is to provide legal representation to indigent defendants. Assigned attorneys are private attorneys who are appointed by the court to represent indigent defendants, often on a pro bono basis. Contract attorneys are private attorneys who are hired to represent indigent defendants for compensation. All states except one (Maine) have public defender systems, with 22 states having stateoperated public defender systems and 27 states having county-operated public defender systems (Langton \& Farole Jr., 2009; Owens et al., 2014). Some may also use assigned attorneys and contract attorneys.

Public defenders represent defendants in a substantial number of cases. For example, a study of defendants in 1996 from the 75 largest counties found that among state felony cases, public defenders represented $68.3 \%$ of defendants, assigned attorneys represented $13.7 \%$ of defendants, and private attorneys represented $17.6 \%$ of defendants, with $0.4 \%$ of cases being self-represented (Harlow, 2000). In 2007, public defenders received almost 5.6 million cases (Langton \& Farole Jr., 2009).

Given the large number of defendants represented by public defenders, it is important to note that studies have found that case outcomes, such as probability of conviction and severity of symptoms, generally do not differ for defendants represented by public defenders versus private attorneys (Cohen, 2014; Hartley, Miller, \& Spohn, 2010; Liang, Long, \& Brame, 2012; Williams, 2002). Examples exist though of public defenders having better outcomes than private attorneys (e.g., Harlow, 2000) and private attorney having better outcomes than public defenders (e.g., Hoffman, Rubin, \& Shepherd, 2005; Williams, 2013). There is also evidence to suggest that public defenders have better outcomes than assigned attorneys (Anderson \& Heaton, 2012; Cohen, 2014; Roach, 2014). Results of studies may vary because of type of crime reviewed, geographic location, and other factors, but contrary to public perception, the type of attorney has not, in fact, been detrimental to defendant outcomes as evidenced by the majority of research on legal representation and court outcomes.

In addition to the U.S. Supreme Court requiring states to provide legal counsel to defendants who cannot afford to hire their own attorneys, it also required by Ake $v$. Oklahoma (1985) that states provide a mental health expert to indigent defendants to conduct a pretrial psychiatric evaluation to be used by defense attorneys to prepare for a potential insanity defense. Evaluations are significant in the U.S. because many persons with mental illness who are arrested are indigent because of high rates of disability and unemployment (Baron \& Salzer, 2002; Hudson, 2005). Consequently, they may need 
the state to provide both legal representation and pretrial psychiatric evaluations and related mental health assistance.

Pretrial psychiatric evaluations of criminal defendants typically address competency to stand trial and criminal responsibility (Melton, Petrila, Poythress, \& Slobogin, 2007). Competency evaluations address the current mental state of defendants and whether it affects their ability to assist attorneys in their own defense. Due process requires such participation, and if they do not have the ability, prosecutors cannot proceed with the criminal case. Dusky v. United States (1960) set the standard for competency that is used in most states and the U.S. federal government (Melton et al., 2007). It requires that defendants must be able to assist attorneys with any defense issue, and must understand the nature of the criminal justice proceedings.

Requesting competency evaluations and being found competent to stand trial has both positive and negative aspects. A positive aspect is that it assures attorneys that their clients are, in fact, able to work with them to prepare defense strategy, provide feedback as prosecution witnesses testify, and provide potential alibi information. These abilities are critical to due process. Such evaluations may also identify the need for treatment that might not otherwise be identified, which may require inpatient or outpatient psychiatric treatment prior to a trial or plea agreement. This potential positive aspect of requesting competency evaluations could be viewed as a negative, in the sense that it may be a manipulation of the criminal justice system in order to obtain needed treatment (Kois, Pearson, Chauhan, Goni, \& Saraydarian, 2013). Regardless, requesting such evaluations can slow down the case's movement through the system. It may take 60 days or longer to complete the evaluation report. If the defendant is found incompetent to stand trial, the trial process may be delayed another six months or more while competency is attempted to be restored by mental health professionals. Depending on the severity of the crime, the defendant could be in custody for a longer period of time than the potential punishment would be in a plea agreement. In addition, having large numbers of incompetent or nonresponsible defendants admitted to public mental health facilities is a concern, since it then severely limits access for the public at large (Parks, Radke, \& Haupt, 2014), which is not an inconsequential concern given diminished resources for social services.

Unlike competency evaluations that consider the defendants' current mental state, evaluations of criminal responsibility assess mental state at the time of the crime to determine whether the accused meets the standard for what is commonly known as an insanity defense. To evaluate criminal responsibility, most states use the American Law Institute (ALI) standard, the M'Naghten standards, or variations of them. Four states have abolished the insanity defense, but courts must still consider mens rea or criminal intent (Packer, 2009).

Positive and negative aspects exist, too, to raising the insanity defense. On the positive side, a successful insanity defense assures that defendants with mental illness who cannot form criminal intent are not convicted and possibly incarcerated. Perlin (1996) summarized the negative aspects of an insanity defense. If the insanity dense is unsuccessful and defendants are convicted of their criminal charges, they are likely to receive significantly longer sentences than defendants tried on similar charges. Next, most defendants who successfully employ the insanity defense are not permitted to 
return to those homes. Rather, they are involuntarily committed to psychiatric hospital, typically a state facility. Finally, many who are hospitalized will be hospitalized longer than they would have been incarcerated in jail or prison had been found guilty.

The critical importance of questions regarding a defendants' ability to assist with their own defense and to understand the roles of the prosecutor, defense counsel, and judge are integral to the concept of justice in the criminal courts. Should there be differences in outcomes between types of counsel, the very underpinnings of the foundation of justice are brought seriously into question. It goes to the very heart of the concern that justice can be bought, and that the indigent are at an inescapable disadvantage. That concern leads to the focus of the current study.

\section{Focus of the Study}

This study adds to the body of knowledge of legal representation of defendants with mental illness by describing their characteristics and identifying differences between defendants represented by public defenders and private. This is accomplished through an examination of pretrial psychiatric evaluations completed with defendants represented by public defenders and private attorneys. It uses information from courtordered pretrial psychiatric evaluations completed in fiscal years 2003 through 2015 by employees of the Missouri Department of Mental Health (DMH) referred to as forensic examiners. It addresses four research questions. First, what is the rate at which requests for DMH pretrial psychiatric evaluations are made for defendants represented by public defenders versus defendants represented by private attorneys? Second, how do defendants represented by public defenders versus private attorneys differ in demographic characteristics, psychiatric diagnosis, treatment history, and crime justice variables? Third, how do the evaluation questions included in court orders vary for defendants represented by public defenders versus private attorneys? Fourth, how do forensic examiner responses to the court-ordered evaluation questions vary for defendants represented by public defenders versus private attorneys?

The research questions are informed within the context of therapeutic jurisprudence (TJ). TJ, defined generally, “.. . explores the impact of the law upon psychological wellbeing" (King \& Wexler, 2010, p. 126), and considers whether law is a "therapeutic agent" (Gould, 1995, p. 84). This application is appropriate since the competency system may be considered a potential diversion from the criminal justice system, as a finding of incompetency diverts defendants from the traditional legal process until such time as either competency is restored or until the court finds that no possibility exists for such restoration of competency. Likewise, a successful insanity defense typically results in defendants being transferred from the criminal justice system to the mental health system.

$\mathrm{TJ}$ as an approach to analyzing the intersections of the criminal justice and mental health systems has been ongoing for approximately 30 years, but there has been little application to the pretrial evaluation context, and specifically not for trial competency or responsibility evaluations (Perlin, 2010). An exception is Gould (1995) who argued that while there are both pros and cons to requesting competency evaluations, ethical considerations abound for the defense attorney in making or recommending that course of action. Wexler $(2005,2006)$ and Perlin (2010) offer cogent arguments for utilizing TJ concepts in analyzing the actions of courtroom workgroup members, including the 
actions of criminal defense attorneys in evaluation contexts. A small body of research has examined how legal and behavioral factors may influence defense counsel in their decision to request a competency evaluation (Bayless \& Polk, 2005; Berman \& Osborne, 1987; Hoge, Bonnie, Poythress, \& Monahan, 1992), and the extent to which defense attorneys considered "...the client's best interest from a mental health standpoint as opposed to following a strict legal definition of competency" (Bayless \& Polk, 2005, p. 313). Studies found that attorneys assessed defendants' ability to meet the Dusky standards in some form but also considered some behavioral actions in making that evaluation request in order to identify treatment needs. Examples of behaviors included unsuitable actions, self-harm, substance abuse, and cognitive disorganization (Berman \& Osborne, 1987). The current study seeks to apply the concept of TJ to enhance the discussion of potential explanations of the results. This extension of TJ to this aspect of the intersection of the criminal justice and mental health fields is both appropriate and needed.

\section{Background on Missouri's Systems}

The Missouri State Public Defenders System (MSPD) is responsible for representing indigent defendants charged with crimes in Missouri (State of Missouri Public Defender Commission, 2015). One or more factors are used to determine if defendants are eligible for representation through MSPD, including income, debt, assets, ability to post bond, receipt of public assistance, and number of dependents. From July 1, 2014 to June 30, 2015 (FY2015), MSPD employed 376 attorneys and 211 staff members that included investigators, paralegals, clerks, and others, to handle 95,122 trial cases; 3425 appellate matters; and 113 death penalty cases. It also contracts with private attorneys to address a limited number of cases, including 5.15\% in FY2015 at an average cost of $\$ 724$ per case. MSPD's budget of $\$ 39.7$ million includes funds with which to obtain private psychiatric evaluations in competency and responsibility cases.

In Missouri, forensic evaluations, competency to stand trial, criminal responsibility, and related matters are addressed in Missouri Revised Statutes (RSMo, 2015) Chapter 552. Mental illness includes both mental illness and developmental disabilities. Specifically:

The terms "mental disease or defect" include congenital and traumatic mental conditions as well as disease. They do not include an abnormality manifested only by repeated criminal or otherwise antisocial conduct.... The terms "mental disease or defect" do not include alcoholism without psychosis or drug abuse without psychosis or an abnormality manifested only by criminal sexual psychopathy (RSMo 552.010).

Missouri statute also defines competency to stand trial. RSMo 552.020.1 states: "No person who as a result of mental disease or defect lacks capacity to understand the proceedings against him or to assist in his own defense shall be tried, convicted or sentenced for the commission of an offense so long as the incapacity endures." This meets the Dusky standard. RSMo 552.020.11 requires defendants to be admitted to a DMH psychiatric hospital for an initial six-month period for restoration of competency, with an additional six-month commitment if incompetency endures beyond that time. If 
the court finds there is a substantial probability that defendants will be not be competent to stand trial in the reasonably foreseeable future, either civil commitment or guardianship proceedings will be initiated and criminal charges dropped.

Missouri has two codified defenses based on mental impairment: mental disease or defect negating a culpable mental state, known colloquially as the diminished capacity defense, pursuant to RSMo. 552.015.2(8) and mental disease or defect excluding responsibility, known colloquially as the insanity defense, pursuant to RSMo. 552.030. These defenses have different standards and consequences. The diminished capacity defense simply means that as a result of a mental disease or defect the defendant did not have the requisite mental state for the crime charged but rather a lower level of intent and, thus, should be convicted of a lesser offense. The insanity defense is an affirmative defense, which if successful, results in a finding of not guilty by reason of mental disease or defect and the defendant is not subject to "punishment" for the crime charged. The standard in Missouri is that the defendant, as a result of a mental disease or defect, was unable to know and appreciate the nature, quality or wrongfulness of his/her conduct at the time of the crime (RSMo 552.030.1). If found not responsible, defendants are transferred to $\mathrm{DMH}$ custody and placed in a $\mathrm{DMH}$ psychiatric hospital (RSMo 552.040). Insanity acquittees can be discharged into the community only with a court-ordered conditional release, and released from any supervision only by the committing criminal court.

Missouri law requires $\mathrm{DMH}$ to provide one pretrial psychiatric evaluation at no charge. The defense attorney or prosecuting attorney can request the court to order a competency evaluation, or the court can order the evaluation on its own motion. Only the defense attorney or the prosecuting attorney can request an evaluation on the issue of criminal responsibility. However, the prosecuting attorney is only entitled to a courtordered DMH criminal responsibility evaluation if the defense has raised the issue by pleading not guilty by reason of mental disease or defect (i.e., using the insanity defense) or by requesting a court-ordered criminal responsibility evaluation. Regardless of the party requesting court-ordered $\mathrm{DMH}$ pretrial psychiatric evaluations, copies of the completed evaluation reports are provided to the defense attorney, the prosecuting attorney, and the court (RSMo 552.020.6). Missouri meets the Ake v. Oklahoma requirement through public defenders having resources to hire private pretrial psychiatric evaluations. The provision of pretrial psychiatric evaluations by $\mathrm{DMH}$ forensic examiners does not meet the Ake v. Oklahoma requirement because the evaluation reports are court-ordered and shared with the prosecuting attorney and the court. In addition, Ake mandates that defense attorneys have access to mental health professionals to assist in evaluation, preparation, and presentation of the defense, which is not the function of the work of DMH forensic examiners (Williams v. State of Missouri, 2008). The accessibility requirement has been reinforced in McWilliams $v$. Dunn (2017), wherein the U.S. Supreme Court reversed and remanded Mr. McWilliams' case to determine if such lack of access to a mental health professional warranted his potential release. These issues continue to be relevant in today's criminal justice system.

Next, RSMo 552.020.2 sets the professional requirements for completing evaluations for the courts. The evaluator must be a doctoral-level clinical psychologist, a psychiatrist, or a physician with at least one year of training or experience working with people with a mental illness, developmental disability, or intellectual disability. DMH 
forensic examiners are organized according to what Melton et al. (2007) refer to as an institution-based, outpatient model, with defendants evaluated on an outpatient basis in interview rooms at the psychiatric hospitals, or at the jails or prisons. Defendants are hospitalized for the evaluations only when clinically necessary. In FY2015, DMH forensic examiners completed 490 pretrial psychiatric evaluations, inclusive of attorney type.

\section{Methods}

\section{Data Source}

DMH forensic examiners complete pretrial psychiatric evaluation reports ordered by the criminal courts as well as a range of psychiatric evaluations of DMH clients. Upon completion of evaluation reports, a DMH hospital staff member completes a one-page form that summarizes key elements of the report, including defendant characteristics, psychiatric diagnosis and treatment history, criminal justice variables, court-ordered evaluation questions and forensic examiner responses, and other information. The forms are submitted to the DMH central office where they are entered into an electronic database. This study includes pretrial evaluation reports submitted to the courts in FY2003 through FY2015. During this 13-year period, forensic examiners completed 5656 psychiatric evaluations. Three groupings of evaluations were excluded from this study. First, $4.2 \%(N=238)$ of evaluations were not used because the evaluations were either ordered by DMH for internal reviews of current clients or they did not address areas of competency or responsibility. Second, within this smaller sample, $10.6 \%(N=$ 576) of evaluations were missing attorney status. Third, within the further reduced sample, $8.5 \%(N=412)$ of evaluations were excluded because they were second or third evaluations of defendants for the same criminal act, typically for reevaluations of competency after the courts found them to the incompetent to stand trial and they had been committed to a DMH psychiatric hospital for restoration of competency. Because of the relatively large number of missing attorney cases, a bivariate analysis was conducted that compared the defendant characteristics and evaluation outcomes of defendants with and without missing data. Given the large sample size, only differences of $p$-values of less than or equal to .001 and effect sizes of .10 or higher were considered. Using these standards, differences were found with 1 of 32 variables included in the study. The rate of recommendation of hospitalization was higher for cases with missing attorney data than for those with attorney data, $43.4 \%$ and $26.8 \%$, respectively $(p<.001$; Cramer's $V=.107)$. Consequently, attorney data was mostly missing at random. This study is a secondary analysis of the summaries of the 4430 pretrial psychiatric evaluation reports remaining after deletion of the three groups.

\section{Variables}

Demographic Characteristics Demographic characteristic variables include age in years at time of referral for the evaluation; sex coded as male and female; race coded as White, African American, and other; and highest level of education attained coded as eighth grade or less, some high school, a high school diploma or its equivalency, some 
college, or college graduate. For the logistic regression analyses, race was recoded as White and minority and education was coded as high school equivalency or higher and less than high school.

Psychiatric Diagnosis and Treatment History The dataset included up to two psychiatric diagnoses. These are recoded into nine categories based upon the fourth edition of Diagnostic and statistical manual of mental disorders (American Psychiatric Association, 1994), which was applicable at the time forensic examiners conducted the evaluations. Categories include five primary diagnoses (psychotic disorders, mood disorders, anxiety disorders, dementia and other cognitive disorders, and developmental disabilities), two that are typically secondary diagnoses (substance-related disorders and personality disorders), and no psychiatric diagnosis of any type. Each is a separate dichotomous variable indicating the presence or absence of that diagnostic category. Treatment history is coded as five dichotomous variables indicating whether or not defendants had a history of treatment of the following types: inpatient psychiatric treatment, outpatient psychiatric treatment, substance-related treatment, treatment in a facility for persons with developmental disabilities, and no treatment.

Criminal Justice Variables One variable is criminal history, coded as whether or not defendants had a felony conviction prior to the offense for which the pretrial psychiatric evaluation was requested. A second category of variables is the criminal charge or charges that led to the referral for an evaluation. The database contained up to three crime codes for each defendant. These crimes are recoded in two ways. One is the class of crime of the most serious of the three crimes based on Missouri statute, which, in order of most to least serious, is murder, class A felonies, class B felonies, class C felonies, class D felonies, and misdemeanors. For the logistic regression analyses, class of crime was treated as a continuous variable with numbers assigned on the basis of the maximum years of a prison term for each class of crime, which ranged from 1 to 30 . Because murder can result in a sentence of life without parole, this crime was assigned a numeric value of 50. Next is the specific crime or crimes that led to referral. Defendants committed 33 types of crimes. Reported in this study are crimes that had a frequency of $10 \%$ or greater, which totaled three. Next is the county of the state circuit court that ordered the pretrial psychiatric evaluation. Missouri has 115 counties, which we recode into one of three categories: counties with large urban cities $(N=2)$, suburban counties or counties with medium size cities $(N=5)$, and rural counties $(N=108)$. For the logistic regression analyses, two dummy variables were created for county, including urban counties (yes/no) and suburban counties (yes/no), with rural counties as the comparison variable. A final criminal justice variable is custody status of defendants at the time of the evaluation, with categories including living in the community on bond, incarceration in a county jail, and being held in a state institution, which could be a state prison or DMH psychiatric hospital. For the logistic regression analyses, two dummy variables were created for custody status, including on bond (yes/ no) and state institution (yes/no), with county jail as the comparison variable.

Evaluation Questions and Responses The next set of variables relates to the specific evaluation questions included in the court order. Dichotomous variables are created for each of the other following four questions: (1) whether or not the court order asked for 
an opinion on "mental disease or defect" as described in RSMo 552.010; (2) whether or not the court order asked for an opinion on competency to stand trial as described in RSMo 552.020; (3) whether or not the court order asked for an opinion on criminal responsibility as described in RSMo 552.030; and (4) whether or not the court order asked for an opinion on hospitalization in a DMH psychiatric hospital pending trial. No missing data existed for these four variables. Next, dichotomous variables are created for forensic examiner responses to the four questions when the question was asked in the court-order and answered by the forensic examiner with a yes or no response. These are coded as (1) whether or not the forensic examiner found the defendant to have a "mental disease or defect", (2) whether or not the forensic examiner found the defendant to be incompetent to stand trial, (3) whether or not the forensic examiner found the defendant lacked criminal responsibility, and (4) whether or not the forensic examiner found the defendant required hospitalization pending trial. For these latter four variables, data is coded as missing data when the forensic examiner did not offer a yes or no opinion because either the court order did not request an opinion or the forensic examiner deferred on it. Otherwise, the four variables had no missing data.

\section{Defendant Description}

Overall, the mean age of the 4430 defendants in the study was 36.4 years $(S D=13.2)$ and ranged from 14 years to 93.2 years. Thirty-two defendants were under the age of 18 at the time of the evaluation, with 30 being 17 years of age, but all were being tried as adults. Most defendants were male $(84.3 \%)$ and were White $(62.9 \%)$, with $34.3 \%$ being African American and $2.9 \%$ of other races. Over one-third (39.4\%) did not have a high school diploma or its equivalency. Rates of primary psychiatric diagnoses included $33.4 \%$ diagnosed with psychotic disorders, $23 \%$ with mood disorders, $11.6 \%$ with anxiety disorders, $7.2 \%$ with developmental disabilities, and $6.1 \%$ with dementia and other cognitive disorders. Rates of secondary diagnoses included $30.1 \%$ diagnosed with substance-related disorders and $11.1 \%$ with personality disorders. Few defendants had no diagnosis of any type $(6.5 \%)$. Only $13.8 \%$ of defendants did not have a treatment history, with the most prominent treatments being inpatient psychiatric treatment $(61 \%)$ and outpatient psychiatric treatment $(56 \%)$. Almost half of defendants $(44.6 \%)$ had felony convictions prior to the crime that led to their pretrial psychiatric evaluations. The distribution of the most serious crime across the six classes of crimes included $7.3 \%$ murder, $22.5 \%$ class A felonies, $18.4 \%$ class B felonies, $27.8 \%$ class $\mathrm{C}$ felonies, $11.5 \%$ class D felonies, and $12.4 \%$ misdemeanors. The most frequent crimes were assault $(26.5 \%)$, weapon offenses $(21.4 \%)$, and sexual offenses (15.9\%), all of which included felony and misdemeanor charges. The majority of defendants were referred from rural counties $(50.2 \%)$, followed by urban counties $(28.4 \%)$ and suburban counties $(21.4 \%)$. Most defendants were housed in county jails at the time of the evaluations $(64.1 \%)$, followed by residing in the community on bond $(27.1 \%)$ and in a state institution $(8.7 \%)$.

\section{Data Analysis}

We conducted two sets of analyses. First are bivariate analyses to identify differences between the characteristics of defendants represented by public defenders and private 
attorneys. Chi-square was used as the test of statistical significance for categorical variables and a t-test was used to determine statistical significance with the one continuous variable. In addition, we calculated effect sizes using Cohen's $d$ for the one continuous variable and Cramer's $V$ for the categorical variables. Given the large sample size, we report findings with $p$-values of less than or equal to .001 and effect sizes of .10 or higher. A second set of analyses are logistic regressions in which dependent variables are the evaluation questions asked and the forensic examiner responses. The independent variable in the logistic regressions is attorney type, and control variables include the demographic, psychiatric diagnosis, treatment history, and criminal justice variables.

\section{Results}

\section{Rate of Evaluation Requests}

Of the 4430 court-ordered requests for pretrial psychiatric evaluations, $57.8 \%$ of defendants were represented by public defenders, with the remaining $42.2 \%$ represented by private attorneys.

\section{Demographic Characteristics}

Defendants represented by public defenders tended to be younger and to have less education. Mean age of defendants represented by public defenders was 35.7 years $(S D=12.4)$ compared to 37.4 years $(S D=14.2)$ among those represented by private attorneys. Defendants represented by public defenders were less likely to have a high school education or its equivalency than defendants represented by private attorneys (55.2\% and $67.4 \%$, respectively). Differences between defendants represented by public defenders and private attorneys did not meet statistical significance and/or effect size standards for sex and race. Table 1 includes additional information on demographic characteristics of defendants represented by public defenders and private attorneys.

\section{Psychiatric Diagnosis and Treatment History}

Defendants represented by public defenders were more likely to be diagnosed with psychotic disorders (40.3\% and $23.9 \%$, respectively), while defendants represented by private attorneys were more likely to be diagnosed with mood disorders $(28.3 \%$ and $19.2 \%$, respectively) and anxiety disorders (16\% and $8.4 \%$, respectively). Differences between defendants represented by public defenders and private attorneys did not meet statistical significance and/or effect size standards for dementia and other cognitive disorders, developmental disorders, substance-related disorders, personality disorders, and being diagnosed with no disorder.

Differences in treatment history between attorney types existed for inpatient psychiatric treatment. Defendants represented by public defenders were more likely to have experienced inpatient treatment compared to defendants represented by private 
Table 1 Demographic characteristics by attorney status

\begin{tabular}{llll}
\hline Characteristic & Public defender (N=2560) & $\begin{array}{l}\text { Private attorney } \\
(N=1870)\end{array}$ & Effect size \\
\hline Mean age at court order $(S D) *$ & $35.7(12.4)$ & $37.4(14.2)$ & .128 \\
$\quad$ Range: & 14.0 to 93.2 & 16.3 to 90.5 & \\
$\quad$ missing data & $(N=1)$ & & \\
Sex & $15.6 \%$ & $15.9 \%$ & \\
Female & $84.4 \%$ & $84.1 \%$ & \\
Male & & & \\
Race $*$ & $60.0 \%$ & $66.8 \%$ & .170 \\
White & $37.4 \%$ & $29.9 \%$ & \\
African American & $2.6 \%$ & $3.3 \%$ & $(N=5)$ \\
Other & $(N=2)$ & & \\
missing data & & $7.2 \%$ & \\
Education * & $12.1 \%$ & $25.4 \%$ & \\
8th grade or less & $32.6 \%$ & $50.9 \%$ & \\
Some high school & $47.9 \%$ & $10.9 \%$ & \\
High school or equivalency & $5.1 \%$ & $5.6 \%$ & $(N=68)$ \\
Some college & $2.2 \%$ & & \\
College graduate & $(N=189)$ & & \\
missing data & & & \\
\hline
\end{tabular}

$* p \leq .001$

attorneys (65.5\% and 54.9\%, respectively). Differences between defendants represented by public defenders and private attorneys did not meet statistical significance and/or effect size standards for outpatient psychiatric treatment, substance-related treatment, developmental disability facility, and no treatment history. See Table 2 for more detailed information on psychiatric diagnoses and treatment history.

\section{Criminal Justice Information}

Defendants represented by public defenders were more likely to be referred by courts in urban $(30.8 \%$ and $25.1 \%$, respectively) or rural counties $(53.8 \%$ and $45.2 \%$, respectively), while defendants represented by private attorneys were more likely to be referred by courts in suburban counties (29.7\% and $15.4 \%$, respectively). In addition, at the time of the evaluations, defendants represented by public defenders were more likely to be housed in county jail $(73.6 \%$ and $51.3 \%$, respectively) or in a state correctional or DMH faculty (11.2\% and $5.3 \%$, respectively), while defendants represented by private attorneys were more likely to be residing in the community on bond ( $43.4 \%$ and $15.2 \%$, respectively). Differences between defendants represented by public defenders and private attorneys did not meet statistical significance and/or effect size standards for prior felony convictions, class of crimes, and most frequent crime categories. Table 3 includes additional criminal justice information. 
Table 2 Psychiatric Diagnosis and Treatment History by Attorney Status

\begin{tabular}{|c|c|c|c|}
\hline Characteristic & $\begin{array}{l}\text { Public defender } \\
(N=2560)\end{array}$ & $\begin{array}{l}\text { Private attorney } \\
(N=1870)\end{array}$ & Effect size \\
\hline \multicolumn{4}{|l|}{ Psychiatric diagnosis } \\
\hline Psychotic disorders * & $40.3 \%$ & $23.9 \%$ & .171 \\
\hline Mood disorders * & $19.2 \%$ & $28.3 \%$ & .107 \\
\hline Anxiety disorders $*$ & $8.4 \%$ & $16.0 \%$ & .117 \\
\hline Dementia and other cognitive disorders & $5.2 \%$ & $7.2 \%$ & \\
\hline Developmental disabilities $*$ & $9.0 \%$ & $4.7 \%$ & \\
\hline Substance-related disorders * & $27.4 \%$ & $33.8 \%$ & \\
\hline Personality disorders & $11.5 \%$ & $10.5 \%$ & \\
\hline No psychiatric diagnosis of any type & $5.5 \%$ & $7.8 \%$ & \\
\hline missing data all diagnoses & $(N=35)$ & $(N=16)$ & \\
\hline \multicolumn{4}{|l|}{ Treatment history } \\
\hline Inpatient psychiatric treatment $*$ & $65.5 \%$ & $54.9 \%$ & .107 \\
\hline Outpatient psychiatric treatment & $54.5 \%$ & $58.1 \%$ & \\
\hline Substance-related treatment & $27.2 \%$ & $27.8 \%$ & \\
\hline Developmental disability facility $*$ & $4.1 \%$ & $2.1 \%$ & \\
\hline No mental health treatment $*$ & $11.9 \%$ & $16.3 \%$ & \\
\hline missing data all treatment history & $(N=4)$ & & \\
\hline
\end{tabular}

$* p \leq .001$

\section{Evaluation Questions and Responses}

Differences between defendants represented by public defenders and private attorneys in the evaluation questions included in court orders existed for 1 of 4 questions. Defendants represented by public defenders were less likely to have court orders that included requests for criminal responsibility evaluations $(41.4 \%$ and $64.3 \%$, respectively). This finding held even when controlling for demographic, psychiatric diagnosis, treatment history, and criminal justice variables in a logistic regression analysis. Being represented by public defenders reduced the odds of criminal responsibility being included in the court order (odds ratio $=.447, p<.001$; model: $\chi^{2}[25, N=$ $3900]=547.6, p<.001$; Nagelkerke $\left.\mathrm{R}^{2}=.175\right)$. Differences between defendants represented by public defenders and private attorneys did not meet statistical significance and/or effect sizes standards for the questions addressing "mental disease or defect," competency to stand trial, and hospitalization pending trial. All three of these latter questions were included in almost all evaluation requests for defendants represented by both public defenders and private attorneys.

Among those instances in which court orders included evaluation questions that forensic examiners answered with yes or no responses, differences between defendants represented by public defenders and private attorneys existed for 3 of 4 response types in the bivariate analyses, although one result did not stand when controlling for demographic, psychiatric diagnosis, treatment history, and criminal justice variables in logistic regression analyses. Compared to defendants represented by private 
Table 3 Crime justice variables by attorney status

\begin{tabular}{|c|c|c|c|}
\hline Characteristic & $\begin{array}{l}\text { Public defender } \\
(N=2560)\end{array}$ & $\begin{array}{l}\text { Private attorney } \\
(N=1870)\end{array}$ & Effect size \\
\hline Prior felony conviction $*$ & $47.7 \%$ & $40.6 \%$ & \\
\hline missing data & $(N=157)$ & $(N=49)$ & \\
\hline \multicolumn{4}{|l|}{ Class of crime ${ }^{a}$} \\
\hline Murder & $7.2 \%$ & $7.5 \%$ & \\
\hline Class A felonies & $21.0 \%$ & $24.7 \%$ & \\
\hline Class B felonies & $19.0 \%$ & $17.6 \%$ & \\
\hline Class C felonies & $28.3 \%$ & $27.1 \%$ & \\
\hline Class D felonies & $11.2 \%$ & $12.0 \%$ & \\
\hline Misdemeanors & $13.4 \%$ & $11.2 \%$ & \\
\hline missing data & $(N=9)$ & $(N=5)$ & \\
\hline \multicolumn{4}{|l|}{ Most frequent crime categories ${ }^{b}$} \\
\hline Assault & $25.2 \%$ & $28.2 \%$ & \\
\hline Weapon offenses & $20.0 \%$ & $23.3 \%$ & \\
\hline Sexual offenses & $15.2 \%$ & $16.8 \%$ & \\
\hline missing data all categories & $(N=9)$ & $(N=5)$ & \\
\hline \multicolumn{4}{|l|}{ County of jurisdiction * } \\
\hline Urban & $30.8 \%$ & $25.1 \%$ & .173 \\
\hline Suburban & $15.4 \%$ & $29.7 \%$ & \\
\hline Rural & $53.8 \%$ & $45.2 \%$ & \\
\hline missing data & $(N=2)$ & & \\
\hline \multicolumn{4}{|l|}{ Custody status * } \\
\hline In community on bond & $15.2 \%$ & $43.4 \%$ & .317 \\
\hline In county jail & $73.6 \%$ & $51.3 \%$ & \\
\hline In state correctional or DMH facility & $11.2 \%$ & $5.3 \%$ & \\
\hline missing data & $(N=35)$ & $(N=19)$ & \\
\hline
\end{tabular}

\footnotetext{
${ }^{a}$ Based upon the most serious crime if defendants had multiple charges

${ }^{\mathrm{b}}$ Includes all criminal charges if defendants were charged with multiple offenses. Included are those with a frequency of $10 \%$ or higher

$* p \leq .001$
}

attorneys, defendants represented by public defenders were more likely to receive a forensic examiner opinion indicating the presence of a "mental disease or defect" (65.2\% and 53.4\%, respectively). However, type of attorney did not affect the odds of an opinion of "mental disease or defect" when controlling for other variables in the logistic regression analysis (odds ratio $=1.103 ; p=.341$ ). Defendants represented by public defenders were more likely to have an opinion of incompetent to stand trial (43.6 and $25.8 \%$, respectively) in the bivariate analyses. This finding was confirmed in the logistic regression analysis where being represented by a public defender increased the odds of an opinion of incompetent to stand trial (odds ratio $=1.684, p<.001$; model: $\chi^{2}[25, N=3793]=1655.1, p<.001 ;$ Nagelkerke $\left.\mathrm{R}^{2}=.491\right)$. Differences in an opinion 
of not criminally responsible between defendants represented by public defenders and private attorneys were not statistically significant in both the bivariate and logistic regression analyses (odds ratio $=.789 ; p=.266$ ). Finally, defendants represented by public defenders were more likely to receive an opinion of needing hospitalization pending trial (35.3\% and $20.7 \%$, respectively). This result was confirmed in the logistic regression analysis, where defendants with a public defender had an increased odds of an opinion of a recommendation of hospitalization pending trial (odds ratio $=1.505, p<.001$; model: $\chi^{2}[25, N=3764]=1183.4, p<.001$; Nagelkerke $\left.\mathrm{R}^{2}=.395\right)$. Table 4 includes more bivariate results on evaluation questions included in court orders and forensic examiner responses.

\section{Discussion}

Defendants represented by public defenders constituted $57.8 \%$ of the 4430 pretrial psychiatric evaluations completed by DMH forensic examiners between FY2003 and FY2015, with the remaining represented by private attorneys. To provide a context for these percentages, 71,464 new criminal cases were assigned to Missouri public defenders in FY2015 (State of Missouri Public Defender Commission, 2015). A report from Missouri's Office of State Courts Administrator (2015) listed 197,140 criminal cases filed in the same timeframe. This equates to $36 \%$ of criminal cases being assigned to public defenders. Defendants represented by public defenders consisted of $58.5 \%$ of the 432 DMH pretrial psychiatric evaluations completed in FY2015. In some ways, the overrepresentation of defendants represented by public defenders in pretrial psychiatric evaluations relative to the total number of crimes committed is expected. It seems appropriate that defendants with public defenders, who are indigent, would be more likely to avail themselves to psychiatric evaluations at no cost to them, while

Table 4 Evaluation questions asked and examiner responses by attorney status

\begin{tabular}{llll}
\hline Characteristic & Public Defender & Private Attorney & Effect Size \\
\hline Evaluation questions asked & & & \\
$\quad$ Mental disease or defect & $99.8 \%$ & $99.5 \%$ & $97.7 \%$ \\
$\quad$ Competency to stand trial & $98.6 \%$ & $64.3 \%$ & .226 \\
$\quad$ Criminal responsibility * & $41.4 \%$ & $96.9 \%$ & .120 \\
$\quad$ Hospitalization pending trial & $97.2 \%$ & & .184 \\
Forensic examiner responses a & & $53.4 \%(N=1845)$ & \\
$\quad$ Has a mental disease or defect * & $65.2 \%(N=2520)$ & $25.8 \%(N=1811)$ & .159 \\
$\quad$ Incompetent to stand trial * & $43.6 \%(N=2484)$ & $12.5 \%(N=862)$ & \\
$\quad$ Not criminally responsible & $17.2 \%(N=663)$ & $20.7 \%(N=1798)$ & \\
Needs hospitalization pending trial * & $35.3 \%(N=2460)$ & & \\
\end{tabular}

\footnotetext{
${ }^{\text {a }}$ Percentage is based on the number of cases in which the court order included the question and the forensic examiner gave a yes or no response. $N$ represents the total of yes and no responses. No missing data exists $* p \leq .001$
} 
defendants who have the means to hire a private attorney may also choose to obtain a private psychiatric evaluation.

Feeney and Jackson (1991) argued that with the exception of wealthy defendants who can afford teams of high-priced attorneys and investigators, outcomes for defendants represented by private attorneys are only marginally different, if at all, from defendants represented by public defenders. Similarly, Cohen (2014) found relatively few demographic and criminal justice differences between clients by attorney type. Neither study, however, examined the requesting of psychiatric evaluations or work with defendants with mental illness. The findings from the sample of defendants referred for DMH pretrial psychiatric evaluations included in this study do not support their assertions. Compared to defendants represented by private attorneys, defendants represented by public defenders were more likely to be younger and to have less education. In general, prior trial competency research found older defendants were more likely to be opined as incompetent to stand trial (Cooper \& Zapf, 2003), but in the current study public defender clients were younger, yet still had an increased chance of an incompetency recommendation. Defendants represented by public defenders were also more likely to be diagnosed with psychotic disorders. Consistent with this diagnosis, they were more likely to have had prior inpatient psychiatric treatment and to have higher rates of recommendations by forensic examiners as having a "mental disease or defect", being incompetent to stand trial, and needing psychiatric hospitalization pending trial. Research found prior psychiatric hospitalizations and psychotic disorders are predictors for a greater likelihood of incompetency opinions (Cooper \& Zapf, 2003). Therefore, it is logical that public defender clients will have increased chances of incompetency to stand trial opinions, which is exactly what the current study found. Likewise, this difference in clinical presentation may account for the high number of forensic evaluations requested by public defenders, in that public defenders represent defendants in $36 \%$ of criminal cases in Missouri, but defendants represented by public defenders constituted $58 \%$ of the evaluations.

The combination of at-risk demographic factors and more severe psychiatric disorders decreases the ability of people with mental illness to obtain employment or it relegates them to low paying jobs (Baron \& Salzer, 2002), thus requiring the services of a public defender. While such psychiatric disorders may qualify some individuals for disability payments through federal programs, such as Supplemental Security Income or Social Security Disability Insurance, the payments are typically low, especially for people without a work history or a history of low-paying jobs. It is not surprising then that defendants represented by public defenders were less likely to post bond and more likely to be jailed pending trial.

Three of four questions included in court-ordered requests for pretrial psychiatric evaluations were asked at high rates $(96.9 \%$ to $99.8 \%)$ with little differences between defendants represented by public defenders and by private attorneys. These included whether or not defendants had a "mental disease or defect", competency to stand trial, and hospitalization pending trial. The one exception among the four questions was for opinions regarding criminal responsibility. Overall, this question was asked in only about half of all the court-ordered evaluation requests. In one regard, this is not surprising because of the potential life-time inpatient commitment to DMH psychiatric hospitals or on conditional release of a successful insanity defense. Some other states limit the commitment to the maximum length of sentence had the defendant been 
convicted, while other states use a less stringent civil commitment criteria for release (Brakel, 1988; Linhorst, 1997). However, requests for criminal responsibility evaluations were asked at a much higher rate for defendants represented by private attorneys than by public defenders ( $64.3 \%$ and $41.4 \%$, respectively).

Several possible explanations exist for this. One is that public defenders may request pretrial psychiatric evaluations by private practitioners at a higher rate than do private attorneys. If the private evaluation indicates nonresponsibility, then public defenders may not pursue a DMH evaluation. Alternatively, if the private evaluation supports the insanity defense, then public defenders may submit that private evaluation, and the request for a $\mathrm{DMH}$ responsibility evaluation may have been made by the prosecuting attorney to confirm or refute the appropriateness of the defendant's private evaluation claim of nonresponsibility.

A second explanation is that public defenders are more aware of the consequences of a successful insanity defense, that is, an indefinite commitment to $\mathrm{DMH}$, and thus are able to provide defendants with more accurate information. Not all states utilize an indefinite commitment for non-responsibility findings, which may allow other states to effectively by-pass this issue. The insanity defense is rarely used, being raised in less than $1 \%$ of felony cases (Steadman et al., 1993); consequently, many private attorneys will not have experience with it. Even if most public defenders are not directly involved with the insanity defense, a statewide public defender office, such as Missouri's, can share information about the consequences of a successful insanity defense and the experiences of those attorneys who used it. These explanations may suggest that public defenders, and not private attorneys, are considering therapeutic consequences of potential life-time commitments to a psychiatric hospital by not pursuing such evaluations. Such an outcome is potentially one envisioned by Perlin (2010) in his discussion of when not to raise the competency question. This study extends that consideration to the responsibility question, which could be driven by TJ because of indefinite statutory commitment requirements in Missouri and some other states.

A third explanation is that private defense attorneys may be more likely to request both competency and responsibility evaluations at the same time, while public defenders may be more likely to first request a DMH evaluation for competency only and later make a determination whether to request a court ordered DMH responsibility evaluation. If the DMH competency evaluation indicates the absence of a "mental disease or defect" under RSMo 552.010, the public defender may not request a DMH evaluation on the issue of responsibility, thereby limiting to at least some extent the 5 th and 6th Amendment rights waivers that occur with these evaluations. On the other hand, if the DMH competency evaluation reflected a diagnosis that could be the basis of the insanity defense, the public defender may then choose to request a responsibility evaluation if the defendant supports the potential use of that defense option. With this additional information, a lawyer is much better able to counsel a client on the potential risks and benefits of a court ordered responsibility evaluation making the additional 5 th and 6th Amendment rights waiver inherent in the additional evaluation more knowing and voluntary. This outcome could also suggest the informal consideration of TJ principles, if an explanation is provided to the defendant regarding that lengthy hospitalization potential. It may also suggest that private attorneys may be more likely to use such evaluations for purposes of trial strategy as envisioned by Bayless and Polk (2005) and Hoge et al. (1992) than are public defenders. 
An additional explanation revolves around whether attorneys assume a more paternalistic versus legal advocacy stance (Bayless \& Polk, 2005). Attorneys assuming a paternalistic stance may argue that an indefinite commitment to $\mathrm{DMH}$ may be in the best interest from a quality of life perspective for defendants who have a severe mental illness and who, for example, may have had periods of untreated mental illness, homelessness, malnutrition, and co-occurring substance abuse or health issues, and thus try to persuade defendants to enter this plea. Attorneys, in essence, would be leveraging the U.S. criminal justice system to gain access to diminishing mental health treatment resources (Redlich, Steadman, Robbins, \& Swanson, 2006). Consistent with this view, some have argued that in certain situations, attorneys should raise the insanity defense over the objection of their clients (Ross, 1998). The alternative legal advocacy view focuses on partnering with defendants to provide them the information, resources, and support needed for defendants to make the best decision for themselves, especially with regard to the outcome of the case and when alternatives to the insanity defense may lead to much shorter periods of incarceration. If private attorneys are more likely to assume a paternalistic stance than public defenders, it would explain the difference in requests for responsibility evaluations. A final explanation may be that public defenders limit their requests for responsibility evaluations to only the most severe crimes, while private attorneys make the request for a wider range of crimes. This explanation was empirically tested and both attorney types asked for responsibility opinions at consistent rates throughout the six classes of crimes (effect size $=.026$ ).

The U.S. criminal justice system has seen an increase in the number of specialty courts, such as drug courts, mental health courts, veterans courts, domestic violence courts, and other types (Strong, Rantala, \& Kyckelhahn, 2016; Wiener \& Brank, 2013). There is increasing attention as to whether defendants served by these courts have the ability to meaningfully participate in the legal processes and understand what their participation gains them, or loses them, when they do participate or do not participate (Barber-Rioja \& Rotter, 2014). Those concerns are consistent with the meaningful participation of the defendants detailed in this study regarding requests for responsibility evaluations. While the concept of TJ has enhanced the potential explanations of the study's findings, the overall application of TJ to competency and responsibility decisions should be an increasing focus of research. Wexler (2005) suggests increasing the use of TJ in law school clinics that work with defendants with mental illness. Thus, for lawyers in training, such considerations could become commonplace and increase the TJ focus in the criminal process, including at the pretrial phase of a case when deciding whether or not to request such psychiatric evaluations.

Attorneys, whether public or private, should receive continuing legal education regarding the treatment options, commitment criteria, and release probabilities in their specific jurisdiction to fully inform their clients. Attorneys should also, at a minimum, self-assess to assure that they understand their own potential bias or philosophy in making any recommendations, and whether they intend to be a "problem-solver" and serve a rehabilitation role while simultaneously retaining their advocacy function (King \& Wexler, 2010, p. 130). If the problem solving function is paramount, then an integrative approach with mental health professionals to address the potential treatment needs and options is suggested (Wexler, 2005). 


\section{Conclusion}

In conclusion, this study documents the high level of disability and disadvantage of defendants with mental illness, particularly those represented by public defenders. Additional research is needed to determine the reasons for differences in referral rates for responsibility evaluations for defendants represented by the two attorney types. These results are important for the criminal justice system no matter in what state the defendant is found, since all states utilize a competency standard based upon Dusky, and most states utilize a variation of the insanity standard. Therefore, defense counsel, prosecutors, and the judiciary should be aware of any such differences. This study goes to the heart of the American Bar Association's's (2016)Criminal Justice Standards for Mental Health, which state: "Officials throughout the criminal justice system should recognize that people with mental disorders have special needs that must be reconciled with the goals of ensuring accountability for conduct, respect for civil liberties, and public safety" (Standard 7-1.2[a]). These ABA Standards were recently revised to prominently place the concerns and needs of those defendants with mental health issues in the criminal justice system in the minds of criminal justice professionals. Such differences between attorney types could be based on differential knowledge of the competency and responsibility systems and their consequences, on the use of different legal strategies, on different philosophical positions when working with offenders with mental illness, or differential reliance on private pretrial psychiatric evaluations, or other reasons. Also, research comparing public defenders and private attorneys should be extended to include private pretrial psychiatric evaluations used by both public defenders and private attorneys as well as those conducted by state departments of mental health. Differences between defendants represented by public defenders and private attorneys could be greater or lesser if private evaluations are included.

Consequently, several limitations and future research directions are suggested. A limitation of this study is that its results are not generalizable to all defendants with mental illness who receive psychiatric evaluations since it omitted those who received only private psychiatric evaluations. Another limitation may be that there is no analysis as to whether there are differences that exist between forensic examiners as to their opinions by attorney type. It is also unknown as to how many DMH forensic examiners also have a private practice completing such evaluations, and how, or if, differences by attorney type exist within that pool of evaluations. Another limitation to this study is not knowing whether defense attorneys, prosecutors, or the courts in the case of competency evaluations order the pretrial evaluations. A final area of research is to determine the relationship between actual court findings of incompetency or criminal nonresponsibility, as opposed to forensic examiner recommendations, and the role that types of legal representation play in those decisions. This also reflects a limitation to the current study as actual court dispositions of the cases analyzed were not part of the dataset.

Surely the goal should be, no matter what state is considering these important questions of competency and responsibility, that no wrongful convictions occur for defendants with mental illness. A defendant's inability to participate in their defense 
strategy lowers the potential success of reaching that goal. The results of this study can help to continue the discussion to assure that it does not matter which attorney type represents each defendant.

\section{References}

Ake v. Oklahoma, 470 U.S. 68; 105 S.Ct. 1087; 84 L.Ed.2d 53;1985 U.S. Lexis 52; 53 U.S.L.W. 4179 (1985). American Bar Association. (2016). American Bar Association Criminal Justice Standards on Mental Health ( $4^{\text {th }}$ ed.). Chapter 7. Chicago: American Bar Association.

American Psychiatric Association. (1994). Diagnostic and statistical manual of mental disorders (4th ed.). Washington, DC: Author.

Anderson, J., \& Heaton, P. (2012). How much difference does the lawyer make? The effect of defense council on murder case outcomes. The Yale Law Journal, 122(1), 154-187.

Barber-Rioja, V., \& Rotter, M. (2014). A therapeutic approach to jurisprudence: A differential thinking model of sanctions and rewards. International Journal of Forensic Mental Health, 13, 272-278.

Baron, R. C., \& Salzer, M. S. (2002). Accounting for unemployment among people with mental illness. Behavioral Sciences \& the Law, 20, 585-599.

Bayless, C. M., \& Polk, O. E. (2005). Attorneys' self-reported perspectives and criteria for requesting competency evaluations in criminal defense cases. Criminal Justice Review, 30(3), 312-324.

Berman, L. M., \& Osborne, Y. H. (1987). Attorneys' referrals for competency to stand trial evaluations: Comparisons of referred and nonreferred clients. Behavioral Sciences \& the Law, 5(3), 373-380.

Brakel, S. J. (1988). After the verdict: Dispositional decisions regarding criminal defendants acquitted by reason of insanity. DePaul Law Review, 37(2), 181-258.

Cohen, T. H. (2014). Who is better at defending criminals? Does type of defense attorney matter in terms of producing favorable case outcomes. Criminal Justice Policy Review, 25(1), 29-58.

Cooper, V. G., \& Zapf, P. A. (2003). Predictor variables in competency to stand trial decisions. Law and Human Behavior, 27(4), 423-436.

Dusky v. United States, 362 U.S. 402; 80 S.Ct. 788; 4 L.Ed.2d 824; 1960 U.S. Lexis 1307 (1960).

Feeney, F., \& Jackson, P. G. (1991). Public defenders, assigned counsel, retained counsel: Does the type of criminal defense counsel matter? Rutgers Law Journal, 22(2), 361-456.

Gideon v. Wainwright, 372 U.S. 335; 83 S.Ct. 792; 9 L.Ed.2d 799 (1963); 5951 U.S. Lexis 1942; 23 Ohio Op.2d 258; 93 A.L.R.2d 733.

Gould, K. A. (1995). A therapeutic jurisprudence analysis of competency evaluation requests: The defense attorney's dilemma. International Journal of Law and Psychiatry, 18(1), 83-100.

Harlow, C. W. (2000). Defense counsel in criminal cases (NCJ 179023). Office of Justice Programs, Bureau of Justice Statistics: U.S. Department of Justice.

Hartley, R. D., Miller, H. V., \& Spohn, C. (2010). Do you get what you pay for? Type of counsel and its effect on criminal court outcomes. Journal of Criminal Justice, 38(5), 1063-1070.

Hoffman, M. B., Rubin, P. H., \& Shepherd, J. M. (2005). An empirical study of public defender effectiveness: Self-selection by the "marginally indigent". The Ohio State Journal of Criminal Law, 3, 223-255.

Hoge, S. K., Bonnie, R. J., Poythress, N., \& Monahan, J. (1992). Attorney-client decision-making in criminal cases: Client competence and participation as perceived by their attorneys. Behavioral Sciences \& the Law, 10, 385-394.

Hudson, C. G. (2005). Socioeconomic status and mental illness: Tests of the social causation and selection hypotheses. American Journal of Orthopsychiatry, 75(1), 3-18.

King, M., \& Wexler, D. (2010). Therapeutic jurisprudence. In J. M. Brown \& E. A. Campbell (Eds.), The Cambridge handbook of forensic psychology (pp. 126-132). New York: Cambridge University Press.

Kois, L., Pearson, J., Chauhan, P., Goni, M., \& Saraydarian, L. (2013). Competency to stand trial among female inpatients. Law and Human Behavior, 37(4), 231-240.

Langton, L., \& Farole, D., Jr. (2009). Public defender offices, 2007 - Statistical tables (NCJ 228538). U.S. Department of Justice, Office of Justice Programs, Bureau of Justice Statistics. Revised June 17, 2010.

Liang, B., Long, M. A., \& Brame, W. (2012). Is it legal representation or clients? An empirical testing of clients' performance and their legal representation in Tulsa County drug and DUI programs. American Journal of Criminal Justice, 37, 544-561.

Linhorst, D. M. (1997). The impact of system design on the characteristics of Missouri's insanity acquittees. The Journal of the American Academy of Psychiatry and the Law, 25(4), 509-529. 
McWilliams v. Dunn, 582 U.S. (2017); 137 S.Ct. 1240; 197 L.Ed.2d 461; 2017 U.S. Lexis 1693; 85 U.S.L.W. 3415.

Melton, G. B., Petrila, J., Poythress, N. G., \& Slobogin, C. (2007). Psychological evaluations for the courts: A handbook for mental health professionals and lawyers (3rd ed.). New York: Gilford Press.

Missouri Revised Statutes (2015). Chapter 552: Criminal Proceeding Involving Mental Illness.

Office of State Courts Administrator. (2015). 2015 Criminal Cases Annual Report. Retrieved December 3, 2017 from https://www.courts.mo.gov/page.jsp?id=96462.

Owens, S. D., Accetta, E., Charles, J. J., \& Shoemaker, S. E. (2014). Indigent defense services in the United States, FY2008-2012 (NCJ 246683). U.S. Department of Justice, Office of Justice Programs, Bureau of Justice Statistics.

Packer, I. K. (2009). Evaluation of criminal responsibly. New York: Oxford University Press.

Parks, J., Radke, A. Q., \& Haupt, M. B. (2014). The vital role of state psychiatric hospitals. Alexandria: National Association of State Mental Health Program Directors (NASMHPD) Medical Directors Council.

Perlin, M. L. (1996). Myths, realities, and the political world: The anthropology of insanity defense attitudes. Bulletin of the American Academy of Psychiatry and the Law, 24(1), 5-26.

Perlin, M. L. (2010). "Too stubborn to ever be governed by enforced insanity": Some therapeutic jurisprudence dilemmas in the representation of criminal defendants in incompetency and insanity cases. International Journal of Law and Psychiatry, 33, 475-481.

Redlich, A. D., Steadman, H. J., Robbins, P. C., \& Swanson, J. W. (2006). Use of the criminal justice system to leverage mental health treatment: Effects on treatment adherence and satisfaction. The Journal of the American Academy of Psychiatry and the Law, 34, 292-299.

Roach, M. A. (2014). Indigent defense counsel, attorney quality, and defendant outcomes. American Law and Economics Review, 16(2), 577-619.

Ross, J. (1998). Autonomy versus a client's best interests: The defense lawyer's dilemma when mentally ill clients seek to control their defense. American Criminal Law Review, 35, 1343-1347.

State of Missouri Public Defender Commission. (2015). Fiscal year 2015 Annual Report Retrieved December 3, 2017 from https://archive.org/details/2015MOPublicDefenderAnnRpt.

Steadman, H. J., McGreevy, M. A., Morrissey, J. P., Callahan, L. A., Robbins, P. C., \& Cirincione, C. (1993). Before and after Hinckley: Evaluating insanity defense reform. New York: Guilford Press.

Strong, S. M., Rantala, R. R., \& Kyckelhahn, T. (2016). Census of problem-solving courts, 2012 (NCJ 249803). Washington, DC: Office of Justice Statistics, Office of Justice Programs, U.S. Department of Justice.

Wexler, D. B. (2005). Therapeutic jurisprudence and the rehabilitative role of the criminal defense lawyer. St. Thomas Law Review, 17(3), 743-774.

Wexler, D. B. (2006). Therapeutic jurisprudence. In A. Taylor (Ed.), Justice as a basic human need (pp. 6169). New York: Nova Science Publishers.

Wiener, R. L., \& Brank, E. M. (2013). Problem solving courts: Social science and legal perspectives. New York: Springer.

Williams, M. R. (2002). A comparison of sentencing outcomes for defendants with public defenders versus retained counsel in a Florida circuit court. Justice System Journal, 23(2), 249-257.

Williams, M. R. (2013). The effectiveness of public defenders in four Florida counties. Journal of Criminal Justice, 41, 205-212.

Williams v. State of Missouri, 254 S.W.3d 70 (Mo.Ct.App. 2008).

Dr. Donald M. Linhorst is the Director of the School of Social Work at Saint Louis University. He received his Ph.D. in Political Science from University of Missouri - St Louis, and his MSW from Saint Louis University. His research interests include the intersection of criminal justice and mental health, the empowerment of people with mental illness, and specifically those individuals served by mental health courts, jail based substance abuse treatment programs, and those committed by criminal courts to mental health systems. Dr. Linhorst spend many years working in community psychiatric programs, and mental health department institutions.

Dr. Ann Dirks-Linhorst received her Ph.D. in Criminology and Criminal Justice from University of Missouri - St Louis; and her law degree from University of Missouri - Kansas City. She served as an Assistant Attorney General for the State of Missouri representing the Missouri Department of Mental Health, and then directly worked with that Department as the Forensic Director, with responsibility for coordinating pretrial evaluations of competency and/or responsibility, managing insanity acquittees, etc. Her research interests include the 
intersection of the mental health and criminal justice systems. She is currently a Professor in Criminal Justice Studies at Southern Illinois University Edwardsville.

Ms. Susan McGraugh is the supervisor of the Criminal Defense Clinic at Saint Louis University School of Law, where she is also a faculty member. She received her BA from Drake University, and her law degree from Washington University in St. Louis School of Law. She practiced law for many years with the Missouri Public Defender's Office.

Lauren Choate received her MSW degree from Saint Louis University School of Social Work. She currently serves as Adjunct Faculty and Social Worker with Saint Louis University Legal Clinics, including the Criminal Defense Clinic.

Ms Sarah E. Riley assisted with this article while in Graduate School at Saint Louis University School of Social Work. She has now earned her MSW degree from that institution. 